\title{
Evaluating electronic learning environments from a Lifelong Learning perspective
}

\author{
Carolyn Dowling \\ Australian Catholic University, 115 Victoria Parade, Fitzroy Victoria 3165, Australia
}

c.dowling@patrick.acu.edu.au

\begin{abstract}
For many educators and indeed for many learners, ICT appears to hold the key to the successful implementation of Lifelong Learning. The capacity of the technology to overcome temporal and spatial constraints has obvious synergies with the need to learn at a time, place and rate determined by individual requirements rather than by formal structures. This paper examines the extent to which the quality of electronic environments designed specifically for this type of learning should be judged according to the same criteria and parameters that we customarily use in evaluating face-to-face teaching.
\end{abstract}

Key words: agents, computer-mediated communication, evaluation, face-to-face, Information and Communication Technology, knowledge, learning environment, Lifelong Learning, online learning, online teaching, quality, social construction

\section{INTRODUCTION}

The quest for greater accountability in education on the part both of its consumers and of those responsible for its funding, has led to an increased emphasis in many countries on a range of processes and procedures which come under the general heading of 'quality assurance'. This is often seen as particularly important in relation to determining the status of online learning environments in comparison to their face-to-face equivalents. Given the wide range of criteria against which educational endeavours might 
potentially be benchmarked, the quest for standards against which 'quality' can be assessed is mounting a significant challenge to researchers. For example, acknowledging the fact that, "Evaluation ... has become increasingly important in the current quality-driven context of higher education" Oliver et al (1995; p. 199) attempt to chart a course through the complexities of qualitative and quantitative methodologies, formative and summative evaluation and so on, by means of the compilation of an evaluation 'toolkit'. This has been designed to assist the researcher in considering and choosing from a wide range of optional approaches to the evaluation and ultimate comparison of different types of learning environments. While such initiatives are undoubtedly helpful, there remain a number of unanswered questions concerning the notion of equivalence both of process and of outcome between face-to-face and online learning environments.

Firstly, we need to clarify the extent to which the criteria used in evaluating face-to-face learning environments are appropriate for use in electronic contexts. Secondly, given the potential importance of online learning to strategies that might facilitate a community orientation towards Lifelong Learning, we need to consider whether the fostering in students of skills appropriate to Lifelong Learning necessitates broader changes in our conception of what constitutes a 'quality' learning environment, whether face-to-face or computer mediated.

\section{EQUIVALENCE AND QUALITY}

To many educators, a key aspect of quality in the provision of online learning is the degree to which the experience of the learner mirrors, in as many respects as possible, that provided by the face-to-face classroom. In addition to the provision of interactivity, great store is often placed on the creation of an interface featuring clearly identifiable metaphorical equivalents of elements of physically existing educational institutions, such as libraries, meeting rooms and student lounges. The justification for this is frequently framed in terms of equity of provision to all students which, it is suggested, can best be achieved through the highest possible degree of replication of experience between the different modes of course offering. In a recent discussion between this author and staff engaged in the translation of a unit of study from face-to-face to electronic mode, it was argued that this derives from the 'fact' that the face-to-face learning experience encompasses the accumulated wisdom of decades of research into educational practice, and is therefore a model which should be faithfully followed. Further, it was felt that a high degree of apparent replication of the 
face to face environment would ensure favourable judgments from quality assurance bodies. (Dowling 2002).

Several interesting and important questions derive from a consideration of these claims, including the issue of whether or not the characteristics of traditional face-to-face classrooms are the most appropriate to foster in learning environments designed to meet the needs of the Lifelong Learner.

\section{Identifying and measuring equivalence}

While the educators mentioned above placed great importance on apparent equivalence of process, and were concerned to map this equivalence as faithfully as possible from the 'ideal' represented by traditional learning environments onto their electronic counterparts, it can be argued that this is in part an artefact of their personal lack of familiarity with electronic environments. For increasing numbers of students, accustomed to electronically mediated interaction in many aspects of their lives, the attempted replication of traditional learning environments may not, in fact, facilitate their learning. Rather, it may represent a failure to capitalise on the information-seeking and communicative skills that they are accustomed to exercising in other contexts, including the contemporary workplace, and that are likely to be of increasing importance in terms of a Lifelong Learning scenario emphasising the processes rather than the content of learning. Further, there is an abundance of research indicating that electronic interactions should not be regarded as the precise equivalents of their faceto-face counterparts (Dowling 2000), (Dowling 2000A). This suggests that notions of replication, in addition to being undesirable, might also be basically unachievable.

If replication of the outward processes of face-to-face teaching is not an appropriate measure of equivalence of quality, what are the alternatives? In practical terms, the ultimate measure of equivalence as recognised informally by most stakeholders lies in comparability of outcomes. Do the students studying online perform as creditably on identifiable measures of learning, most often interpreted as a fairly traditional range of 'content' and context-specific 'skills', as their more traditionally educated peers? It can be argued that this approach is somewhat naïve, and fails to take cognisance of subtle distinctions in the types of learning taking place within the different contexts. Nevertheless, for many students, parents and employers it represents the 'bottom line'.

Perhaps the greatest weakness of this point of view is its failure to take into account the students' performance in those 'social' and 'process oriented' aspects of learning and performance such as participation, 
negotiation and collaboration that figure so strongly in the contemporary rhetoric of both education and the workplace. In addition there is often insufficient consideration paid to their ability to apply generic problem solving skills to novel content, and the capacity to interact effectively with online material and information is for the most part ignored. Outcomes such as these are arguably of greater relevance to Lifelong Learning than is the acquisition of domain-specific skills and content knowledge. Interestingly, they are also aspects of the quality of the learning experience that can be far more readily measured and evaluated in relation to online environments than face-to-face. Further, it can be argued that, within these contexts, they can be even more readily and effectively assessed than more traditional learning outcomes. Benigno and Trentin (2000), for instance, identify the two particularly significant aspects of evaluation of online courses as being the evaluation of learning and the evaluation of the participants' performance or participation within the course. In so claiming, they acknowledge the richness of data available for undertaking the latter task by comparison with what exists for more traditional modes of pedagogy while lamenting that, by contrast, "Verifying learning is a difficult task" (p. 263). However, while the online environment undoubtedly provides a rich resource of data for measuring processes of interaction both with information and with other participants in the learning process, we lack evidence at this stage concerning the degree to which these apparently more generic outcomes are actually transferable to off-line environments.

Even if they are not fully comparable or transferable, we may still wish to acknowledge that developing skills in interacting and learning online is of value in itself, particularly given the obvious synergies between these capabilities and the needs of the Lifelong Learner. If this is the case, then we need to further consider the relationship between equivalence and quality in evaluating online environments.

\section{Socially mediated learning in the face-to-face and electronic classroom}

If face-to-face and electronic learning environments cannot sensibly be regarded as equivalent, are there characteristics of each that can make a special contribution to the development of generic, transferable skills relevant to Lifelong Learning within a social context?

The assumption that traditional face-to-face learning environments provide the most effective model of interaction is easy to challenge in a number of respects, although we need to guard against perceiving these contexts solely from the perspective of the teacher. At university level, for instance, the mass lecture is clearly intended to provide little opportunity for 
interactivity beyond the one-way delivery of information from the lecturer to the student. In many of these contexts, however, there is actually a great deal of other communication going on through such means as whispered conversation, note-passing and, in recent times, text messaging. As is the case with more legitimate forms of interactivity within educational environments, some of these exchanges are concerned with the course content, while others are not. This is a form of social and intellectual engagement which, although un-mandated, can nevertheless have desirable pedagogical consequences, and may indeed particularly suit the learning styles of some students.

The guided interactions characteristic of smaller scale face to face classrooms typical of a school, or a tutorial, are the more usual models for the interactive components of online learning environments. Both on and offline, these incorporate the potential for facilitation or direction by the teacher, for the exercise of some control over participation, and for the monitoring of interactions.

Students participating in a recent evaluation of a unit taught in mixed mode by this author revealed some interesting perspectives on classroom interactivity. Not surprisingly, a number of them felt that they did not always experience face-to-face learning environments as being highly interactive. Interestingly though, while some regretted this, others claimed that it suited them very well, and that they felt that they learned more 'efficiently' in minimally interactive settings such as large lectures.

Others acknowledged the interactivity of the face-to-face classroom, but stated that it was not their preferred way of learning. A number of these students identified the potential for less obligatory interactivity as being an attractive feature of online environments. One specifically lamented the fact that participation in discussion groups had recently been made mandatory in a particular online class (Dowling 2002A). There are clear links to be made between these observations and the concerns raised in the Position Paper on Lifelong Learning regarding the 'lone wolf' learner (Kendall., et al. 2002).

These tensions between accommodating the preferred learning styles of students and insisting that they undertake their learning through activities that we believe to be beneficial to them in the longer term are not new. They are, however, moving closer to the forefront of pedagogical concerns as we focus increasingly on equipping students with 'meta' learning skills appropriate to the concept of Lifelong Learning, rather than concentrating primarily on the acquisition of short term skills and content knowledge. While we might argue that certain students would benefit from being relieved of the burden of relentless interactivity in the classroom, these are perhaps the very students who need to learn to engage in social and collaborative learning in the interests of their future employability. 


\section{WHAT SPECIAL CONTRIBUTION MIGHT ELECTRONICALLY MEDIATED LEARNING ENVIRONMENTS MAKE TO LIFELONG LEARNING?}

Aside from the more obvious advantages in implementing a flexible 'any time, anywhere' approach to learning, there are more subtle benefits to be derived from online educational environments. The fact that electronically mediated communication is qualitatively different in a number of respects from face to face interactions (Dowling 2000) and (Dowling 2000A) does not necessarily suggest that it is any less effective in facilitating learning. Indeed, as argued earlier, when we consider the primacy of electronic communication both in the workplace and in the personal lives of today's students, this is an extremely 'natural' medium for them in relation both to the acquisition of information and to their preferred mode of social interactivity. Online communication may not 'replicate' its face to face equivalent, but it is becoming the interactive medium of choice particularly for many young people, who embrace with enthusiasm qualities such as speed of response, unstructured access, and the immediate plunge to the core of meaning characteristic of SMS messages. This latter mode of interaction has recently been reported as apparently overtaking email in popularity. "More than 40 per cent of people aged 15 or older in Europe's three biggest economies use short messaging service (SMS) on cellular handsets, while 30 per cent use computer email, says research company GartnerG2" (McLuskey 2002). Such a shift in preferred mode of interaction for both social purposes and in the workplace may mount even greater challenges to the educators of the future as they strive to maintain 'relevance' to their students of all ages and to the world in which they will live, work and continue to learn.

In addition to 'relevance', computer mediated educational environments have a number of other potential advantages in relation to learning at different stages of life. Factors which may encourage particular students to participate more freely in the social negotiations characteristic of knowledge construction include a degree of anonymity and of student control over the persona presented to the rest of the group. In the absence of a number of social 'markers', including indicators of age, some students may feel more able to participate actively in discussion. The ability to opt in or out of discussion, or to interact outside the constraints of 'real time' environments, can also provide the more diffident or reflective student with the temporal 'space' needed in order to contribute a considered response. In the literature of pedagogy much is made of the notion of the 'reflective practitioner'. Are the needs of the 'reflective learner' as well catered for, particularly in face to face learning environments? In terms of Lifelong Learning, one can conjecture that such flexibility might be of particular value, for instance, to 
the complex situation of the more mature learner who is bringing a great deal of prior knowledge to the learning of sophisticated material.

The ability to operate within one's own time frames can also be helpful not just to students but to the teacher in responding to their communications, as can the capacity to communicate as appropriate with either a selected group or with an individual. The ability to structure pedagogical communication in this more 'targeted' way is significantly enhanced in many online environments, and would be particularly beneficial when dealing with student cohorts of mixed ages and prior experience, as is likely to be the case in situations addressing Lifelong Learning needs.

\section{IDENTIFYING QUALITY OUTCOMES ESSENTIAL TO LIFELONG LEARNING}

In considering the evaluation of learning environments from a Lifelong Learning perspective, a tension can sometimes be identified between the acquisition of generically applicable learning skills and the need for 'just-intime' learning of domain-specific skills and content. This can be partially resolved by acknowledging the former as being a desirable pre-condition for the latter, which suggests that, in the early stages of learning, the evaluation of quality outcomes should focus most strongly on students learning 'how to learn', rather than on 'what they learn'. It must be recognised, however, that this is a rather gross simplification of a complex situation.

As noted earlier in this paper, the evaluation of 'process' outcomes is more easily achieved in an online situation due to the capacity for monitoring and recording details of the various forms of interaction that take place both between participants and between learners and the course materials. The irony of this is that, while we may believe that such outcomes are particularly important for younger students, there are also grounds for believing that online environments are suited to more mature students, with younger students gaining special benefit from the support of a face-to-face situation. While detailed discussion of this dilemma is beyond the scope of this paper, it is worth noting in the context of previous discussion that educators in pursuit of data evaluating the efficacy of different educational environments should be wary of equating the outcome most amenable to detailed measurement with the 'best' outcome for the student. In the long term it is clear that both the acquisition of meta-skills and provision for 'justin-time' learning are key aspects of an overall educational strategy designed for Lifelong Learning. 


\section{CONCLUSION}

The evaluation of electronic learning environments from a Lifelong Learning Perspective is a task fraught with complexity. While some issues derive from intrinsic 'differences' between electronically mediated and faceto-face social interaction, others relate to changes in preferred modes of communication both in the workplace and in the broader community. Further challenges are mounted by consideration of differences in the learning styles favoured by individuals, and the degree to which these should be accommodated in the best long term interests of learners and of their communities. Additional questions can be raised in relation to the appropriateness of different modes of pedagogical interaction for learners of different ages, and also to how we should best strike a balance between satisfying the two very different imperatives of 'learning how to learn' and the 'just-in-time' acquisition of new knowledge and skills.

These considerations suggest that there are strong arguments for resisting the temptation to evaluate online learning according to the same criteria as those used in face-to-face situations. Further, if an orientation towards Lifelong Learning is to be taken seriously, we may need to articulate different priorities for evaluation of appropriate outcomes of online as well as face-to-face learning according to the ages and stages of individual learners.

\section{REFERENCES}

Benigno, V. \& Trentin, G. (2000), "The evaluation of online courses", Journal of Computer Assisted Learning, 16 (3), pp. $259-271$.

Dowling, C. (2000), 'Social Interactions and the Construction of Knowledge within Computer Mediated Learning Environments', in Downes, T. \& Watson, D. (eds), Learning in a Networked Society, Kluwer Academic Publishers, Boston, pp. 165 - 174..

Dowling, C. (2000A), 'The role of social interactions in online learning within the Higher Education sector', in Social Aspects of Higher Education - Polish and Australian Reflections, College of Social Sciences and Administration, Warsaw University, Poland.

Dowling, C. (2002) Unpublished personal communication, discussion with academic staff, 25 September, 2002.

Dowling, C. (2002a) Unpublished Student course evaluations, June 2002.

Kendall, M., B. Samways, T. van Weert (Ed.), J. Wibe (2002), Position Paper Lifelong Learning (LLL) Version 1. IFIP, Laxenburg. 
McLuskey, D. (2002), "SMS eats into email in Europe", The Australian IT section, 12.11.2002, p. 6 .

Oliver, M., MacBean, J., Conole, G. \& Harvey, J. (2002), "Using a toolkit to support the evaluation of learning", Journal of Computer Assisted Learning, 18 (2), pp. 199 - 209.

Note: this paper is a further development of work presented at the IFIP working conference Quality Education at a Distance, held at Deakin University, Geelong, inJanuary 2003. 